\title{
Water sector in Morocco: situation and perspectives
}

\author{
Mohamed Alaoui \\ Ministry Of Energy, Mines, Water and Environment, Department Of Water; Morocco
}

Email address:

m.alaoui@water.gov.ma, alaoui.water@gmail.com

\section{To cite this article:}

Mohamed Alaoui. Water Sector in Morocco: Situation and Perspectives. Journal of Water Resources and Ocean Science.

Vol. 2, No. 5, 2013, pp. 108-114. doi: 10.11648/j.wros.20130205.18

\begin{abstract}
Due to its geographic location, Morocco is characterized by a strongly contrasted climate, with its rainfall being highly irregular in space and time. The natural renewable water resources is estimated $22.8 \mathrm{billion}^{3} / \mathrm{yearBCM}^{\mathrm{of}}$ with the contribution of $18 \mathrm{BCM}$ from surface water and $4.8 \mathrm{BCM}$ of groundwater recharge resulting in $730 \mathrm{~m}^{3} / \mathrm{capita} / \mathrm{year}$ which is below the commonly accepted threshold of $1000 \mathrm{~m}^{3} /$ capita /year .Despite the success of the past water policies initiated in the sixties, the future water sector management challenge of the water availability and demand must address the most urgent problems and make water a decisive factor in its sustainable development. In this challenging environment, Morocco has succeeded in ensuring the needs in domestic and industrial water and the development of large-scale irrigated agriculture. Despite these achievements, the factors that determine water availability and water needs have changed so much in recent decades that the country must adapt radically in order to prevent a critical situation. Many solutions exist. Their implementation within an innovative and integrated approach to the whole water sector should allow Morocco to address the most urgent problems and make water a decisive factor in its sustainable development. The new water strategy, implemented in 2009, is expected to support the development of the water needs for the development until 2030 through the implementation of integrated policy combining water conservation and resource mobilization in conventional and unconventional water while respecting the environment and the rights of future generations. The strategy will focus on three components; water demand management and water valuation, supply development and management and preservation and protection of the water sources and the environment. Demand management measures is expected to save $2.4 \mathrm{BCM}$ with contribution of $120 \mathrm{MCM}$ to domestic, construction of 50 dams with additional capacity of1.7 BCM, water transfer of 800 MCM, $400 \mathrm{MCM}$ of desalinated water, $300 \mathrm{MCM}$ of wastewater reuse and increased recharge wastewater. Also implementation of all provisions of Law 10-95 on water, preservation of wetland, drought and flood risk management and enhance information system. These measures are expected to achieve sources sustainability and meeting water requirement.
\end{abstract}

Keywords: Water, Management, Planning, Morocco

\section{Introduction}

Water availability has been not an obstacle to socioeconomic development of Morocco in the past as result of implemented management measures but can pose major challenges for the future demand if nothing is done. Several major challenges and problems are now faced by the water sector relate mainly to the increasing water scarcity of pressured economic development and its impact, exacerbated by climate change, deterioration of water quality due to pollution and, the unsustainable exploitation of groundwater resources, and the waste of consumption trends.

Soil erosion is impacting different regions as, $75 \%$ of the 23 million hectares in mountainous areas are affected by erosion, a third of which are critically affected. The erosion impacts have contributed to the silting of dams, resulting in a loss of storage capacity of about 75 Million Cubic Meter (MCM)/year. The dam reservoirs are designed with dead volumes for storing silt during the life of the works and flushes are also carried out during floods to evacuate part of the silt through the bottom outlets. However, despite these measures, the problem is more acute because of the particular emphasis of erosion by increased demand on soil and vegetation cover

The impact of climate change on water resources has been felt over the past three decades through the intensification of extreme weather events, droughts and floods, and is presented as a major challenge that is being felt acutely now and will continue to be felt in the future. Indeed, the kingdom has faced over the past three decades 20 years with 3 dry periods each lasting four consecutive 
years. This means that the climate situation was exceptionally severe in recent decades and particularly challenging. But Morocco has managed to overcome this critical situation. According to meteorologist's forecasts, Morocco, like the Mediterranean countries, will observe high intensity rainfall generating violent floods threatening lives and infrastructure. In addition to natural hazards, a number of factors exacerbate the vulnerability of floodprone areas, especially the uncontrolled development of land and urbanization in flood areas

Drought has become a structural phenomenon in Morocco and of the last several sequences of drought, the most severe were recorded for the periods 1944-1945, 1981-1985, 1991-1995 and 1998-2001 and 2006-2007. During these years of drought, the rainfall situation was characterized by a generalized deficit that affected all the country. The deficit reached 50 to $60 \%$ in some areas. On the hydrological level, deficits reach more than $70 \%$ in some areas. During these periods, significant declines of flow streams were observed, usually during the months of July and August.

To support the development of the country water requirements, Morocco has been committed to controlling the mobilization of water resources in order to ensure water needs without major difficulties. The strategy adopted in the early 1960s enabled the country to provide significant water infrastructure ensuring to meet the drinking water supply for population, industry and the development of large-scale irrigated agriculture. Considerable efforts have been made also in the protection against flooding of vast territories that suffered significant damages in the past. The expertise developed in recent decades has enabled the country to overcome very critical situations of water shortages and manage sources and demands.

\section{Morocco Water Resources}

Morocco, one of the north Arab countries is characterized by irregular rainfall distribution with $51 \%$ of its amount fall on in less than $7 \%$ of the national territory, and in time, with alternating sequences of years of strong runoff and years of severe drought.

According to the latest estimates, the natural renewable water resources are nearly 22 billion $\mathrm{m}^{3} /$ year(BCM), the equivalent of about $730 \mathrm{~m}^{3} /$ capita/year which is below the commonly accepted threshold of $1000 \mathrm{~m}^{3} /$ capita/year, indicating the occurrence of shortages and impending crises. Rainfall volume is estimated $140 \mathrm{BCM}$ contributing to 22 $\mathrm{BCM}$ of renewable resources of $18 \mathrm{BCM}$ of surface water and $4.8 \mathrm{BCM}$ of groundwater recharge as shown in figure 1 [2].

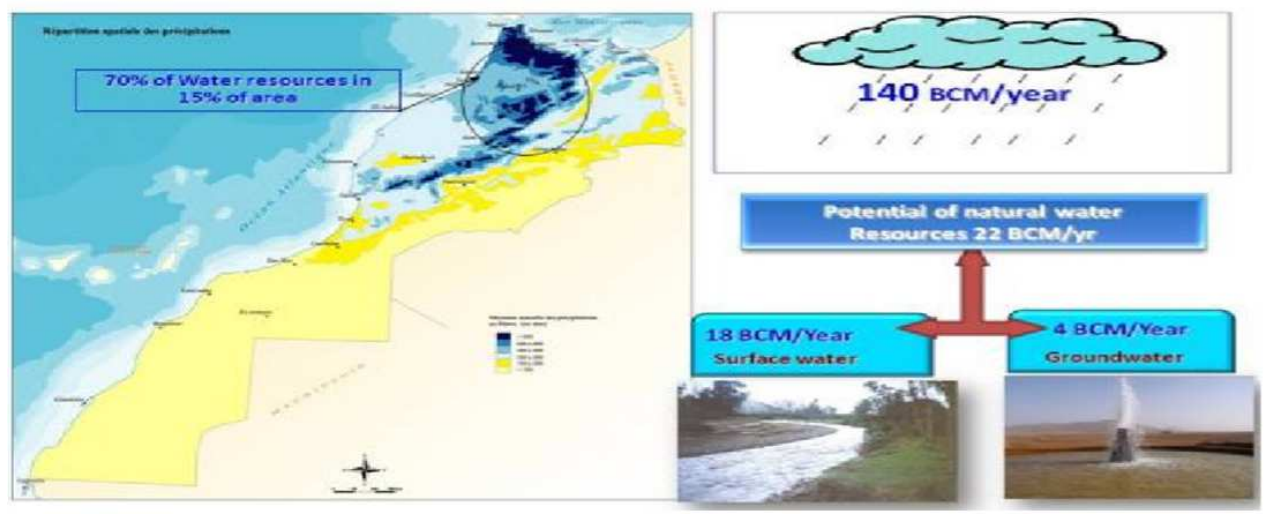

Fig. 1 water potential of Morocco

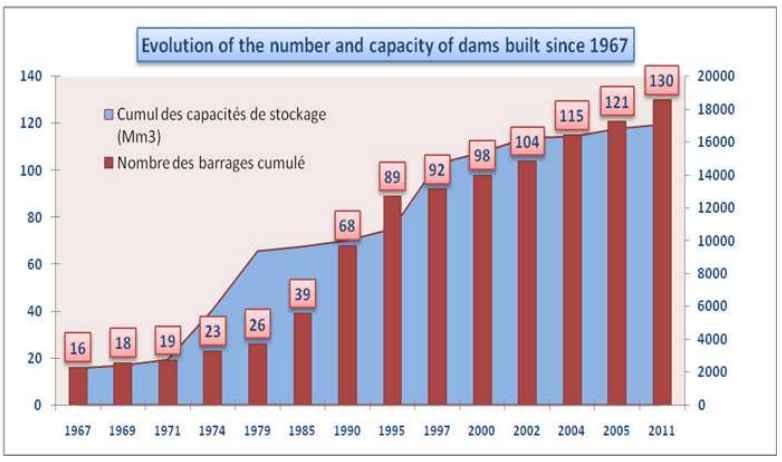

a: Evolution of the number and storage capacity of dams

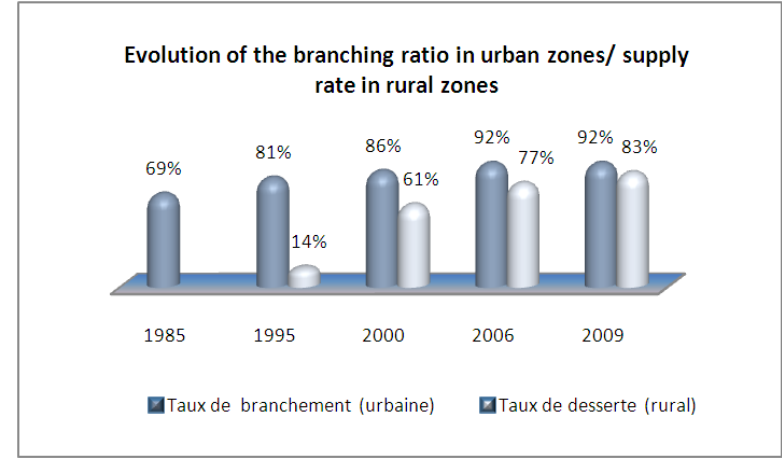

b: Access to drinking water 
The water sector in Morocco has been a central concern of economic policy because of its key role in the water security and support of the country's development, particularly irrigated agriculture.

In this context, Morocco has undertaken since the $60 \mathrm{~s}$ a dynamic policy to give the country a major water infrastructure, improving access to drinking water, meeting the needs of industry and tourism and development of the large-scale irrigation.

Figure 2 shows the achievements in mobilizing surface water [1] and generalization of access to potable water[3].

The current irrigated area is around 1.5 million hectares of which two thirds are equipped by the Government. The distribution by type of schemes and irrigation systems is given below [5]:

Table 1: Distribution of irrigation methods

\begin{tabular}{llllll}
\hline Type & $\begin{array}{l}\text { Gravity irrigation } \\
\text { Area (ha) }\end{array}$ & $\begin{array}{l}\text { Spray irrigation } \\
\text { Area (ha) }\end{array}$ & $\begin{array}{l}\text { Drip irrigation } \\
\text { Area (ha) }\end{array}$ & $\begin{array}{l}\text { Total } \\
\text { Area (ha) }\end{array}$ & Pourcentage \\
\hline Large Hydraulic & 533900 & 113800 & 34900 & 682600 & $47 \%$ \\
Small and Medium Hydraulic & 327200 & 6900 & - & 334100 & $23 \%$ \\
Private Irrigation & 317600 & 16950 & 106900 & 441450 & $30 \%$ \\
Total & 1178700 & 137650 & 141800 & 1458150 & $100 \%$ \\
\hline
\end{tabular}

The hydropower energy production is shown in figure $3[4]$.



Fig. 3: Evolution of installed hydropower capacity (MW)

Significant progress has also been made in the regulatory and institutional fields through the enactment of the Law $10-95$ on water with the creation of river basin agencies with the designated functions of planning, management and preservation of water resources at the level of river basins

In sum, the baseline scenario of the water balance predicts in 2030 a deficit of about 5 billion $\mathrm{m} 3$ that will need to be filled by the implementation of action plans in an integrated strategy taking into account the endogenous and exogenous factors affecting water resources in Morocco. Indeed, as shown in figure 3 below, the current water demand, estimated at $13.7 \mathrm{BCM}$ is met from renewable water mobilized $(11.7 \mathrm{BCM})$ and but also by overexploitation of groundwater (2 BCM). Water demand in 2030 would be $16.2 \mathrm{BCM}$, and if no measures aretaken, the deficit would be 5 BCM[5].


Figure3: Water balance on the horizon 2030_Baseline scenario 


\section{Short and Long Term Comprehensive Management Initiatives}

\subsection{Policy focus}

Morocco has been taken key initiatives recognized at the international level to manage its water resources through appropriate efficient models despite a difficult environment. Action taken consisted of:

* Policy of control and mobilization of water resources through the construction of big reservoirs dams and works for water transfer;

* The development of technical skills and applied scientific research;

* A policy of long-term planning started in the early 1980s that allows decision makers to anticipate water shortages by giving government a long-term visibility (20 to 30 years);

* Achieving significant progress in the regulatory and institutional domain, namely the Law 10-95, which consolidated integrated, participatory and decentralized water resources management through the creation of river basin agencies and the introduction of financial mechanisms for the protection and preservation of water resources.

\subsection{Water Strategy}

To consolidate past successes and to succeed in the aforementioned challenges, a new impetus of a strategy for the reinforcement of the water policy was launched in 2009.

The strategy was elaborated based on three levers, namely:

a. Much more ambitious objectives to consistently meet the country's water needs, but also to continually and sustainably protect against the effects of climate change

b. A dramatic shift in the behavior of resource use and management through a coordinated supply and demand management, covering:

+ The perpetuation of the protection measures and reconstitution of our underground stocks and lake areas

+ Rationalization of water demand

+ Generalization of the treatment and the wastewater reuse in cities

+ An innovating portfolio of mobilization solutions and of access to the resource, combining all the relevant local solutions with better interconnection between regions

+ Proactive protection measures (of the environment, and against floods).

c. A real long-term management of water through:

+ Regularly updated, readily available data (at the national level), of the needs and availabilities in the long run
+ Political commitment, and effort from all stakeholders, supported by adequate regulatory framework and governorship

+ More ambitious public and private funding.

\section{Strategy Analysis}

The main lines of the strategy are structured around the following axes[5]:

\subsection{Water Demand Management and Water Valuation}

In this context of scarcity, ensuring strong water demand management and optimizing water valorization is both urgent and of prime importance; this can be done through technical, legal and financial instruments.

a. In the agricultural domain for instance, the average water savings potential in irrigation amounts to 2.4 $\mathrm{BCM} /$ year

+ Conversion to modern irrigation: a potential of 2 $\mathrm{BCM} / \mathrm{year}$, if 40000 ha per year are upgraded ;

+ Improvement of the adductions to the irrigated areas: potential of $400 \mathrm{MCM} / \mathrm{year}$;

+ Enactment of a volume-based pricing;

+ Communication campaign and training for farmers to help them implement water-saving techniques

+ And for a better valorization of mobilized water resources, bridging the gap between the area dominated by dams and the attached associated infrastructure which is yet to be built ; 108000 ha are programmed

b. For drinking, industrial and touristic water, a potential of a $120 \mathrm{MCM} / \mathrm{year}$ savings is possible by:

+ Improving the distribution networks, with $80 \%$ as a nationwide target;

+ Developing norms and incentives to use water efficient devices: pipes, water-closets, etc.

+ Reform of the water pricing system: with a pricing that enables a more rational use of drinking water and improved cost recovery;

+ Improvement of water use efficiency in industry and tourism units and a push towards larger-scale water reuse;

+ Water-efficient standards for equipment and construction for both residential and industrial sites

\subsection{Supply Development and Management}

Although it is necessary, managing water demand is not the panacea for the quantitative and qualitative challenges bound to water use and one should not exaggerate its virtues. It certainly can defer some investments, but don't allow removing them. Managing demand and water mobilization are a pair of complementary solutions that will have to be optimized. The fundamental question that arises is where to place the cursor for this pair of levers while balancing the need to manage "real" water demand 
generated by the support of socio-economic development needs. To cope with the increased demand for water, two portfolios of solutions exist: water resources managers must first act on the water demand for water savings and then increase the supply by mobilization of additional water resources to fill the gap. Water-saving measures, although they are inexpensive as mobilization technique, are not sufficient to fill in the gap. It is necessary to ensure the adequacy of water resources and needs by mobilizing additional resources in conventional and unconventional water, although they are more expensive than they were in the past. The challenge is how to manage both solutions together.

a. Morocco has made great efforts in mobilizing water resources, and these efforts will be continued under the new water strategy by the mobilization of new water resources on a large scale through:

$+\quad$ The construction of 50 dams by 2030: an additional 1.7 BCM will thus be mobilized.

+ A North-South transfer aimed at sustaining the socioeconomic development of the Bouregreg, Oum ErRbia and Tensift basins: 1st stage of 400 $\mathrm{MCM} /$ year from the oued Sebou, 2nd stage of 400 MCM/year from the Loukkos-Laou ;

b. Small scale water mobilization is also programmed through:

+ The continuation of the small and mid-size dams program: objective to build 1000 small and midsized dams by 2030 ;

+ Rainwater capture: pilot projects before a possible larger-scale deployment as has been done in India and Australia;

+ Extension of the artificial cloud insemination where possible.

The reinforcement of the maintenance of existing infrastructure and the system interconnection will allow for the diversification of water sources and therefore allow for a better security of water supply and important synergies and gains in efficiency.

c. In rural zones, the generalization of access to drinking water will keep to its current pace through the upgrade of existing community systems to ensure that they can continue their operations in the long run and the development of individual systems for the isolated population.

d. Furthermore, the mobilization of unconventional resources is inevitable through:

+ Desalinization of seawater and demineralization of brackish waters: objective of equipping a production potential of nearly $400 \mathrm{Mm}^{3}$ of potable water per year.

+ Reuse of treated wastewater: $300 \mathrm{Mm}^{3} /$ year of treated wastewater for reuse in the watering of golf courses and green space, in addition to reuse in crop irrigation.

+ For the implementation of these action plans, the new strategy of the water sector in Morocco has advocated contracting and the development of public private partnership, especially for the implementation of major transfer projects, desalination, and the program of small dams.

\subsection{The Preservation and Protection of Water Resources, the Environment Sensitive Areas}

\section{a. Preservation and Recovery of Groundwater:}

Protection of groundwater resources is essential from a strategic point of view. During the long drought that hit the country during the 1980s, groundwater use was the only recourse that allowed farmers to maintain the viability of their farms and thus avoid abandoned fields and the acceleration of the rural exodus. However, these withdrawals reached unsustainable levels, exceeding the volumes of annual recharge and drawing on the stock of non-renewable water.

Concerning preservation of groundwater, the proposed medium and long term strategy is based on the development of sustainable management through:

- Strengthening the control system and penalties in the case of overuse;

- Limiting groundwater pumping (revision cost of water prices, elimination of incentivizing subsidies for overuse, rules prohibiting and restricting pumping, efficient technologies...)

- Strengthening the responsibility of the ABH's (Agences de BassinHydrographique) in groundwater management and generalization of groundwater contracts

- Automatic appeal with the water resources of conventional and nonconventional substitution, preferably with the underground resources in order to ease the pressure on the underground resources;

- Programs to artificially regenerate groundwater (storage of $180 \mathrm{Mm}^{3}$ per year);

- Re-injection of treated waste water in the coastal groundwater used for irrigation $\left(100 \mathrm{Mm}^{3}\right.$ by 2030$)$;

- Substitution of the groundwater taken by the ONEP (Office National de l'Eau Potable which is the National Agency for drinking water) to surface water $\left(85 \mathrm{Mm}^{3}\right.$ per year by 2020$)$.

- Protecting the quality of water resources is a strategic objective of the National Water Strategy. This action is based on a deep knowledge of the quality of water resources and sources of pollution and the proposed program for the prevention of and fight against pollution. Specifically, it consists of:

- Accelerating the pace at which the national plan for sanitation and treatment of wastewaters is adopted: Objective of a sanitation access rate of $90 \%$ in 2030 ;

- National Sanitation Plan for Rural Areas: Objective of a sanitation access rate of $90 \%$ in 2030 ;

- National Plan for the Prevention and Fight Against Industrial Pollution;

- Implementation of the National Plan for the Management of Household and Similar Waste. 


\section{b. Safeguarding Watershed, oasis, and Wetlands}

Morocco has numerous areas of inestimable ecological value including wetlands, natural lakes, oases and coastal areas. These sensitive areas are threatened by the pressures exerted by various economic activities on natural resources, threatening both their balance and sustainability. To this end, it is essential to pursue a strategy to safeguard these sensitive areas through:

- $\quad$ Protecting watersheds against erosion by managing them upstream of dams;

- Plan for the protection of water sources;

- Plan for the protection of wetlands and natural lakes;

- Preservation of oases and the fight against desertification;

- Coastal protection;

- Limitation and control of pumping in groundwater resources directly affecting the natural lakes;

- Improving the sourcing of lakes by diverting water courses and developing thresholds and small dams upstream.

\section{Reduction of the Vulnerability to Natural Risks Related to Water and Adaptation to Climate Change}

Given its geographic situation coupled with the effects of climate change, Morocco is confronted with natural risks linked to extreme natural phenomena: flooding and droughts.

i. Improving the protection of persons and property against flooding:

a. Completing the actions set out in the National Plan for Protection against Flooding: target of 20 protected sites per year;

b. Integrating flood risk in planning land use, urban planning and planning of watershed management;

c. Improving knowledge in the field of weather forecasting and urban hydrology;

d. Developing flood warning and emergency plans.

e. Developing financial mechanisms (insurance and disaster funds).

ii. Fight against the effects of drought: management plans by river basin:

Insofar as drought protection is concerned, a concerted national strategy should be initiated by the drought management plans at the level of all river basins, aimed at:

a. Characterization of droughts: identification and proposal of monitoring indicators.

b. Implementation of structural measures: diversification of sources of water supply.

c. Development of contingency plans.

d. Development of financial mechanisms such as insurance and funds for natural disasters.

\subsection{Further Regulatory and Institutional Reforms}

Significant progress has been made through the implementation of the Water Law 10-95, with the introduction of the principles of user-pays and polluter-pays and the establishment of Hydraulic Basin Agencies. However, these advances need to be supplemented by the completion of the legal framework necessary for the implementation of all provisions of Law 10-95 on water.

\subsection{Modernization of Information Systems and Capacity Building and Skills}

The objective is to provide the necessary support for the implementation of the actions of the new strategy. The Administration should follow parallel development of the water sector in human and material resources level, and the modernization of the administration and development of information systems, including in particular the implementation of an Information System on Water for professionals and the general public. The action plan also provides for the modernization of networks measures, strengthening applied research and skills development.

\section{Highlights of the Diagnosis of Moroccan Water Sector}

The analysis of the water sector in Morocco reveals the following structural observations:

+ Morocco's climate varies by region; rainfall is characterized by a high variability in time and space. This situation has been exacerbated by climate change that aggravated extreme events, resulting in dry periods increasingly long, intersected by brief and violent rainstorms that can generate catastrophic floods if they are not controlled;

$+\quad$ in this very challenging context, and to support the development of the country, Morocco has long been involved in the process of controlling its water resources through the implementation of major water infrastructure, which has enabled it to ensure its water needs without major difficulties, even in situations of exceptionally severe water shortages. Indeed, the Kingdom has faced these past thirty years 20 years with 3 dry periods that each lasted four consecutive years;

+ Morocco, where water and its use are part of the deepest roots of an ancient civilization, is now a great hydraulic nation thanks to these achievements. However, this apparent success has left some effects, moreover repairable as long as the Government makes so much will and determination, as in the past, to surpass them;

+ If nothing is done to adapt to this new situation, Morocco may soon find itself in a critical situation in terms of water deficit, overexploitation of groundwater aquifers and environmental degradation.

To avoid compromising its achievements and make water a decisive factor in its sustainable development, Morocco 
has implemented in 2009 a renewed strategy based on three levers:

+ more ambitious goals;

+ a radical change in behavior vis-a-vis the use and management of water resources;

+ the implementation of a real long-term management of water.

The new water strategy in Morocco is based on an integrated and participatory approach. It should enable the country to support its long-term development, meeting the needs of growth and protecting the country against the unpredictable effects of global warming.

\section{Conclusion}

The new strategy of the water sector is expected to support Morocco's development economic growth to large projects and protecting the country against unpredictable effects of global warming.

Actions on water demand and the development of supply, including the Green Morocco Plan,is expected to ensure a sustainable availability of water to meet the future demand. It is planned by 2030 to save 2.5 billion $\mathrm{m}^{3} /$ year through the management of water demand and generate an additional water resource of $2.5 \mathrm{BCM} /$ year through water mobilization.

Mobilization projects will be benefic to basins of Sebou, Bouregreg, OumErRbia and Tensift that have concentration of the industrial, agricultural and tourism activities in the country. In particular, the inter-basin transfer of water will be a key element for economic and social development to support the development of the region of Marrakech and will significantly increase agricultural added value in Doukkala and the Chaouïa regions.

The planned management measures will be implemented by the combination of water supply and demand management oriented towards reducing water deficits and the availability of sufficient resources while ensuring the preservation of the environment.

\section{References}

[1] Direction des Aménagements Hydrauliques (DAH), Ministère de l'Energie, des Mines, de l'Eau et de l'Environnement- Maroc, Grands barrages du Royaume, 2012.

[2] Direction de la Recherche et de la Planification de l'Eau (DRPE), Secrétariat d'Etat chargé de l'Eau et de l'Environnement (SEEE)-Maroc, Evaluation des ressources en eau mobilisables, 2008.

[3] Office National de l'Electricité (ONE)- Maroc, Production de l'Energie Hydro-électrique au Maroc, 2010.

[4] Office National de l'Eau Potable (ONEP)- Maroc Bilan annuel de l'année 2010.

[5] Secrétariat d'Etat chargé de l'Eau et de l'Environnement (SEEE)- Maroc, Etude de la Stratégie Nationale du Secteur de l'Eau, 2008. 